\title{
A Qualitative and Quantitative Review of Equine Facilitated Psychotherapy (EFP) with Children and Adolescents
}

\author{
J.A. Lentini and Michele Knox* \\ University of Toledo College of Medicine 3130 Glendale, Avenue Toledo, OH 43614, USA
}

\begin{abstract}
This paper presents a comprehensive review of the literature on Equine Facilitated Psychotherapy (EFP) with children and adolescents. Methods used in EFP, including traditional mounted, vaulting, husbandry, and unmounted activities are described. The theory and background of EFP is summarized with references to various psychotherapeutic perspectives, such as Freudian, Jungian, cognitive, behaviorist, and psychodynamic models. The status of the research is discussed, and available empirical studies and reports on this topic are summarized. Possible applications to patients with eating disorders, anxiety, trauma history, attention-deficit hyperactivity disorder, oppositional defiant disorder, and delinquency are described. Recommendations are made regarding the direction of future research on EFP.
\end{abstract}

\section{INTRODUCTION}

In the fifth century B.C. horseback riding was used for rehabilitating wounded soldiers [1]. In 1860 Florence Nightingale suggested, "[an] animal is often an excellent companion for the sick" (p. 103). For many years, animals have been used for the therapeutic benefit of humans in a variety of settings. For example, domestic animals are used to help medically ill children in hospitals and the elderly in nursing homes, but it was not until the 1960s that horses were used in the United States for therapeutic purposes [2].

There are many different names to describe therapeutic interactions between humans and animals. The examples listed above describe animal assisted activities (AAA) [3]. In contrast, animal assisted therapy (AAT) is more targeted; it is defined by the Delta Society as a "goal-directed intervention in which an animal that meets specific criteria is an integral part of the treatment process" [4], (p. 264). In AAT the therapist should have a good idea of how working with animals in therapy can be different from traditional psychotherapy. The therapist and the client should have a clear understanding of the therapeutic goals so the client does not confuse it with a social outing. An example of AAT would be a psychotherapy session with a child in which an animal is included in the treatment. For example, Dr. Boris Levinson, the individual often credited as the founder of animal assisted therapy [5], was a child psychologist who began using this method by using his dog "Jingles" to facilitate psychotherapy with children.

By the above definition, Equine Facilitated Psychotherapy (EFP) is a type of AAT. Specifically, EFP is a planned treatment using the horse as an integral part of the psychotherapy process [6]. In addition to the name Equine Facilitated Psychotherapy, also encountered in the literature were

*Address correspondence to this author at the University of Toledo College of Medicine 3130 Glendale, Avenue Toledo, OH 43614, USA; Tel: 419383-3919; Fax: 419-383-3098; E-mail: michele.knox@utoledo.edu the titles Equine-assisted psychotherapy (EAP), equineassisted experiential therapy (EAET), Equine-facilitated therapy (EFT), Equine-assisted learning (EAL), Equinefacilitated learning (EFL), therapeutic riding, psychotherapeutic riding, and hippotherapy (more frequently used to describe physical rehabilitation/therapy); [7].

In EFP, therapists work with horses with different styles and using various theories. Esbjorn [8] reviewed the construct and found that there was a wide variety in the way therapists conceptualized EFP. Not only do the concepts, theories, and names surrounding EFP vary, but also the methods are quite different. Some therapists use un-mounted activities such as herding and leading. Some use nontraditional mounted instruction such as vaulting. Others provide traditional riding instruction. Some focus on care of the animal (husbandry). Some work in groups, others work individually. Many therapists use various combinations of these techniques.

Despite these differences, there is typically agreement in why horses are ideal for psychotherapeutic work: specific equine qualities (such as having a calming effect while requiring total attention to the moment), prospects for metaphor, and relational features [8]. The horse is a prey animal and is also distinctly social. Fight or flight instincts govern the horse's behavior. Naturally living in herds, the horse is accustomed to social experiences. For these reasons, the horse pays great attention to detail. Accordingly, the horse may respond to things that go unnoticed by humans. It is largely because the horse is social and has great attention for detail that it has been domesticated and trained by humans for thousands of years. During the past century, horses have been used in programs aiding persons with physical disabilities. Riders benefit from the gentle rocking motion that may help to relax muscles and improve balance.

The horse's large size is another factor that may contribute to therapeutic benefit; the horse weighs easily a thousand or more pounds. Some theorists contend that the horse's 
power and size provide opportunities for riders to explore issues related to vulnerability, power, and control. Lastly, the straightforward nature of the horse's interactions also may lead to therapeutic gains. The horse is not duplicitous in behavioral interactions, and communication between horse and rider is typically clear and unencumbered [9]. Consequently, horses may be instrumental in retraining humans in direct, honest communication.

\section{METHOD}

This paper will attempt to quantify how well EFP works, and illustrate the way it works by examining the articles, chapters, and books written on the subject of animals and therapy. PsycINFO and MEDLINE were searched using the terms, "equine facilitated psychotherapy" and "animal assisted psychotherapy." Search limits were not restricted. Because few articles were found with this method, a Google internet search was done to access more material. Due to the paucity of results, papers with adults were included, as it was deemed that general findings may be applicable to work with children and adolescents. Search limits were restricted to papers/studies addressing subject matter similar in subject to those found on research databases.

\section{RESULTS}

\section{Qualitative Review}

\section{Theory}

To get a basic understanding of EFP, first some conceptual models and examples will be discussed. Brooks [3] described two conceptual models. The first is a triangle of patient, animal, and therapist in which the therapist observes the behavior of the animal and patient. The behavior of the animal is interpreted to the patient. The effects of the patient's behavior on the animal are reflected to the patient, and the patient is encouraged to reflect on his/her own behavior and affect. The second is the diamond of patient, animal, therapist, and animal handler. The handler has the responsibility to observe and state how the other two are affecting the animal. These methods emphasize the fact that horses in particular (of animals) will be affected by discrepancies between stated intent and observed behavior.

Brooks [3] described a 13 year-old with swearing and rude behavior. This patient's violent and desperate behaviors stemming from fear of rejection did not serve to bring people close to him, but rather pushed people away. The author notes that "animals can teach children about energy, boundaries, how we move our bodies, and the intensity of purpose we bring to others... because they are very sensitive to our energy and how we move around them. If we move too fast or want to touch [them], they often move away from the intensity of the energy we convey... [they] are generally careful about maintaining personal space. However, they are also very curious and will usually approach a human who remains calm and unaggressive" (p. 208-209). The case demonstrates how youths can learn to respect the boundaries of the animal and still have positive interaction with the animal.

Brooks also describes a six year-old who was witness to violence and had problems with behavioral acting out. The animal was used to illustrate healthy touch and an analogy was made to Winnicott's holding environment. This is a safe space, both physical and psychological, which is created by the mother unbeknownst to the infant.

Another study compared a "zoo-group" of children with a control group [10]. Both groups were diagnosed with attention-deficit hyperactivity disorder (ADHD) and conduct disorder. The zoo-group had responsibility for and interaction with a variety of animals for about four hours per week. In three months, the children in the zoo program had a decline of one standard deviation in symptomatology (aggression). During this period the control group had 35 episodes of very aggressive behavior, while the zoo-group had zero. Efficacy reportedly lasted for four years or more.

Work with horses also may be used to break though a client's defensive barriers and require them to develop fresh insights and perspectives for dealing with their old patterns and problems in a way that conventional office therapy does not [11]. In EFP, clients who are behaving in ways that were inconsistent with feelings or thoughts are required to become behaviorally consistent and cooperatively affective in order to work with the horse. While a therapist in office work might not be aware of the dissonance, the horse may display unsettled behavior until the client was internally consistent.

There are a variety of theories as to how and why EFP works. These range from the more physical concepts such as relaxation training taught on horseback, to more intangible ideas like self-awareness, to abstract schemas of unconscious. Roberts [12], for example, describes the horse as a living, breathing biofeedback machine because it externally reveals internal processes in real time. She discussed how nursing students benefited from EFP while learning how the program worked for their child clients. The students had an opportunity to participate in a one day learning experience in horse therapy. According to Roberts, "EFP is not just pet therapy. Horses are unique in their response to humans because they are prey animals, not predators, and their survival demands that they be extremely sensitive to the environment... Horses respond to the internal state of the person, no matter how much the person tries to disguise it" (p. 33). Nursing students were able to take different perspectives on disease and think more creatively about how to help their patients after the program.

Patients with eating disorders describe another treatment population. Christian [13] detailed work with a patient with anorexia who benefited from equine-assisted therapy. In one session, the patient participated in un-mounted activities using problem solving with two therapists, an equine specialist, and three horses simultaneously. Post-session, practical applications to life outside treatment were discussed. In another session, the patient was mounted and had other challenges to solve. Therapists reflected behavior and drew analogies to the patient's life choices. The patient learned to ask for help and be specific in her requests. In addition her attitude improved and she became more optimistic about recovery. Cumella [14] described multiple benefits experienced by clients, including improved self-confidence, self-efficacy, communication, trust, perspective, assertiveness, and boundaries. Another group that may benefit from EFP is clients with problems relating to physical contact or closeness. For example, Bates [15] noted that "being carried" by a horse may have positive associations for women who have shunned physical closeness by humans. 
Vidrine [16] discusses different ways that therapeutic riding may be beneficial. One way is teaching humans to send congruent messages with spoken and body language. Horses communicate almost entirely through body language and are not capable of "double-bind" communication. A horse can be perceived as a very large mirror to promote conscious attention to our specific behaviors. This encourages authentic communication and awareness of our secret intentions. An article by Colclasure [17] provides a quote from the director of the Remuda Ranch equine program, "[Horses] are relational animals that have the natural ability to mirror what our body language is saying. As a result, [we are] able to gain insight into [our] own nonverbal communication and behavior patterns" (p. 2).

Another conceptualization, based on the theorized importance of rhythm as one the first experiences of a developing child, uses equine therapy to build up "body-identity" and help with correcting pre-verbal dialogue. Because humans can actually ride horses, there is a unique relationship there that is not present with a dog or cat. A literal holding and sustaining dynamic is created when a rider has close skin contact with a big and supporting living being. A noted point is that the ratio between the body weight of a horse and rider is not unlike the body weight ratio between a mother and infant. The horse may interact with the individual in an appropriate and physical way that would not be possible for the therapist.

The uninhibited nature and unconditional response of the horse also may be of importance. Quoting Vidrine [16], "Horses are, by and large, naked and unashamed. They get dirty and eat off the ground; they are hairy and at times, sweaty, and breathing hard. They relieve themselves when they need to, their genitals are visible, yet clients can safely physically interact with them on a fairly intimate basis... [and] at a pace they can control... Horses are also not judgmental... and don't know if you are small for your age, or have crooked teeth" (2002, p. 595). These qualities may contribute to greater connectedness and self-acceptance on the part of the rider.

Vidrine [16] also discusses the importance of archetypes as emphasized by Carl Jung. Some old archetypes are the Pegasus and the unicorn. Some modern archetypes are embodied in the stories of The Black Stallion and Misty of Chincoteague. Some particular aspects of horse archetype are: worker, bolter, helper, victim, vital, destructive, sensitive, and panicked. The horse provides a whole new object that may be projected upon with various transferences. Children may imagine horses as magical, powerful, beautiful, brave and strong. These perceptions may contribute to the therapeutic benefits of EFP for children. Vidrine [16] describes her work with children and vaulting and describes some of the noted benefits. Children were very motivated to attend sessions. EFP taught structure, responsibility, routine, care for another (the horse), empathy, safe mistake-making, the value of practice and mastery, discipline, problemsolving, body awareness, visual learning, patience, respect for others choices, creativity, self-esteem, relaxation, the value of completing necessary but unpleasant tasks, selfreflection, and nurturing. In addition, the fact that the EFP was done as a group activity widened the children's “circle of trust" and promoted interpersonal interaction.
Bates [15] uses an analogy comparing the id, ego, and superego to the horse, patient, and therapist, respectively. The horse also may be represented as the object of transference. The rider's repressed id can be associated to horse's impulsivity and vitality. The therapist acts as superego, limiting the rider and horse to safe behavior. Scheidhacker [18] stated, "the therapist's job (superego) is to show the patient (ego) how to control the horse (id) without losing the horse's vitality" (p33). Therapeutic benefits are achieved in part through ego strengthening.

The husbandry and care of an animal can be instrumental in healing. McCormick and McCormick [19] wrote a book called Horse Sense and the Human Heart in which the human-animal bond, including the myth and metaphor of horses are emphasized. The authors promote the Jungian perspective that wild horses represent the instinctual, uncontrollable parts of the unconscious and that the centaur represented an attempt to integrate these separate parts. The McCormicks [19] had many different ways to use horses therapeutically; they varied from simple observation, to animal husbandry and care, to grooming and riding. They chose to use the Spanish Peruvian horse for these interactions because it was known for a "gentle, consistent, trustworthy disposition" (p. 43).

The McCormicks [19] see holding and touch as instrumental in development. Horses can provide this in an appropriate manner to aid in correction of negative experience. They discuss a specific case in which a 16 year-old was helped with a psychotic break. The use of trance in therapy and the horse as a means to help a rider focus into an alpha meditation state are explored. The natural gaits and regular motion of the horse may promote this rhythm and relaxation.

The authors differentiate between the words "feeling" and "emotion." "Feel" comes from "felen" (middle English) and concerns sensations and perceptions. "Emotion" comes from "emouvoir" (middle French) and describes movement and behavior (expressed feeling). The horse's sensitivity may help a person coordinate their emotions with their feelings.

Taylor [9] detailed how horses may be used in family, cognitive behavioral, play and analytic therapy. She related many possible benefits including decreased therapist burnout and increased client motivation. Correspondingly, in a comprehensive paper on the theory and methods of EFP, Karol [20] expounded on the potential therapeutic benefits of EFP for patients working with professional psychotherapists. She notes that very few EFP programs use professionals at a masters or doctorate level. Within the context of traditional psychotherapy, the therapist may use traditional equitation instruction as a therapeutic tool. She states that the use of EFP can help the therapist explore the world of the client on verbal, non-verbal, and pre-verbal levels. Karol [20] reports, "When an advanced-level clinician works in the EFP setting, the therapeutic work can move from a narrow use of cognitive-behavioral techniques, here-and-now therapies, and limited stages of personality development to a more complete psychotherapeutic experience and involvement" (p. 78). It is noted that while Cognitive Behavior Therapy (CBT) and psychodynamic theory could be widely applied to EFP, this multimodal approach to therapy remains very uncommon. She details her work with children in EFP, and describes 
how the sessions are developed and what guiding principles are used. She observes that like traditional psychoanalytic work, in EFP the therapist and client are often free to talk without focusing on the facial expressions and reactions of the therapist.

Karol [20] discusses six aspects of psychodynamic work done in sessions: existential experience (including aspects of biofeedback, here-and-now attention, and immediate communications), unique relationship with the horse, therapeutic relationship with the therapist, nonverbal experiences communicating with the horse, preverbal experiences such as comfort, touch and rhythm, and the use of metaphor. She notes that, "When a child is on top of a horse, sometimes for the first time in [that] child's life, he or she is looking down onto an adult... and can experience power... and an enhanced sense of his/her own body... [furthermore] the horse is also a vulnerable creature and so serves as an apt companion for a child overwhelmed by his or her own sense of vulnerability and imperfections" (p. 81). The relationship with the horse can help develop a child's self-concept and ethics. Transference can occur in relation to the animal and be used therapeutically, and countertransference may develop, especially if the client takes out his/her frustrations on the animal. Nonverbal experiences communicating with the horse refers to how the client listens for and interprets the nonverbal cues of the horse. This can be expanded into how the client relates to the outside world in human behavior and communication. Preverbal experiences relate to the development of object relations. Karol [20] states she sometimes uses music to augment and encourage the development of an internal consistent rhythm. Metaphor can be developed through the child's imagination, through problem-solving, or through story-telling. Metaphor can help bridge the inner and outer worlds of the client. Karol [20] describes EFP as a "theater" in which to explore and catalyze change in the child's universe.

\section{Effects on the Horse}

So EFP may be helpful to humans, but what effect does it have on the horse? Kaiser [21] published a studies concerning the well-being of the horse in which the question "Does therapy using horses cause the horse too much stress?" was addressed. Stress indicators were behaviors such as earspinned, head tossed, etc. The results suggested that equine therapy with at-risk children might stress horses more than simple lessons with recreational riders. This might be due to behaviors that at-risk children sometimes exhibit (e.g., sudden movements, not following safety directions, making loud noises).

Moors [22] did a biography of a horse used for therapy sessions. He was a 16 year-old palomino Quarter Horse gelding named "Yeller." Yeller's disposition was described by a mother of a patient as quiet and calming. He was used as a therapy and lesson horse at the Rancho Vista Equine Center in Fort Collins, Colorado. Previously a 4-H horse, he was described as having a tranquil, steady gait. His owners stated that his toughest challenge was to adjust to many different riders with varying skill levels.

\section{Treatment Populations}

Therapists use EFP as treatment for many different patient populations. Bates [15] reviewed three 1997 studies that showed that once per week riding contact with horses decreased the number of acts of aggression in young people who were "seriously emotionally disturbed." This author concluded that Equine Facilitated Psychotherapy is recommended for use with patients with anorexia, substance abuse, schizophrenia, borderline personality and abusive behavior. EFP was also considered for use in a therapy program for mothers and children to teach parenting and relating.

Tyler [11] found equine therapy was effective in treating patients who were fearful, anxious, depressed, angry, or dissociative. However, Tyler [11] asserts that because the therapy is expensive and time consuming it should be limited to clients who are not reached by conventional methods. An example was provided of a post-traumatic eight-year old boy with conversion disorder affecting speech. He started speaking after his third therapeutic riding session. Treatment with horses was also valuable with "counselor-wise" adolescents with a diagnosis of oppositional defiant disorder.

Besides the diagnoses mentioned above, "special needs" is another area where EFP has been used. A few articles have been published in the online magazine of Arizona State University (ASU) on equine therapy by McCann [23]. She reports on some studies by Crews who is the director of ASU's Alternative Intervention Research Clinic. For six years Crews studied the effect of sports on children with special needs such as ADHD, emotional disorders, low-income and other at-risk groups. She compared golf, swimming, basketball, horseback riding and many others. She stated, "The most consistently positive intervention [with these groups] was the horse therapy" (p. 2).

As mentioned previously, people with eating disorders are another treatment population that may benefit from EFP. Marx [24] discussed the use of horses in therapy at Remuda Ranch, a center for the treatment of eating disorders. It appeared due to case reports that this was effective, but he called for empirical studies to evaluate the effectiveness of this method.

Vidrine [16] summarizes three studies using therapy with horses. One study with children with special education needs showed increased positive behavior among the study participants. Another demonstrated increased social acceptance and self-worth with children with behavioral problems, and a third evidenced improved self-concept among asocial adolescent males. Vidrine [16] suggests that therapy with horses may be particularly effective in treatment of refractory and guarded patients.

Treatment is not limited to mood and childhood disorders. Scheidhacker [18] found that using horseback riding with patients with severe mental illness facilitated treatment gains. Specifically, he used this method in his German clinic with people diagnosed with schizophrenia, resulting in positive outcomes.

Work with male gang youths is described in detail by McCormick and McCormick [19]. They describe their work with severely emotionally disturbed teenagers and Peruvian Paso horses in Calistoga, California. The boys gained knowledge about discipline and education by watching the family unit of a stallion, mare and foal, and then by learning themselves the care and routines of horses. The authors mention that no client was forced to do anything; all were 
Table 1. Summary of Quantitative Sources

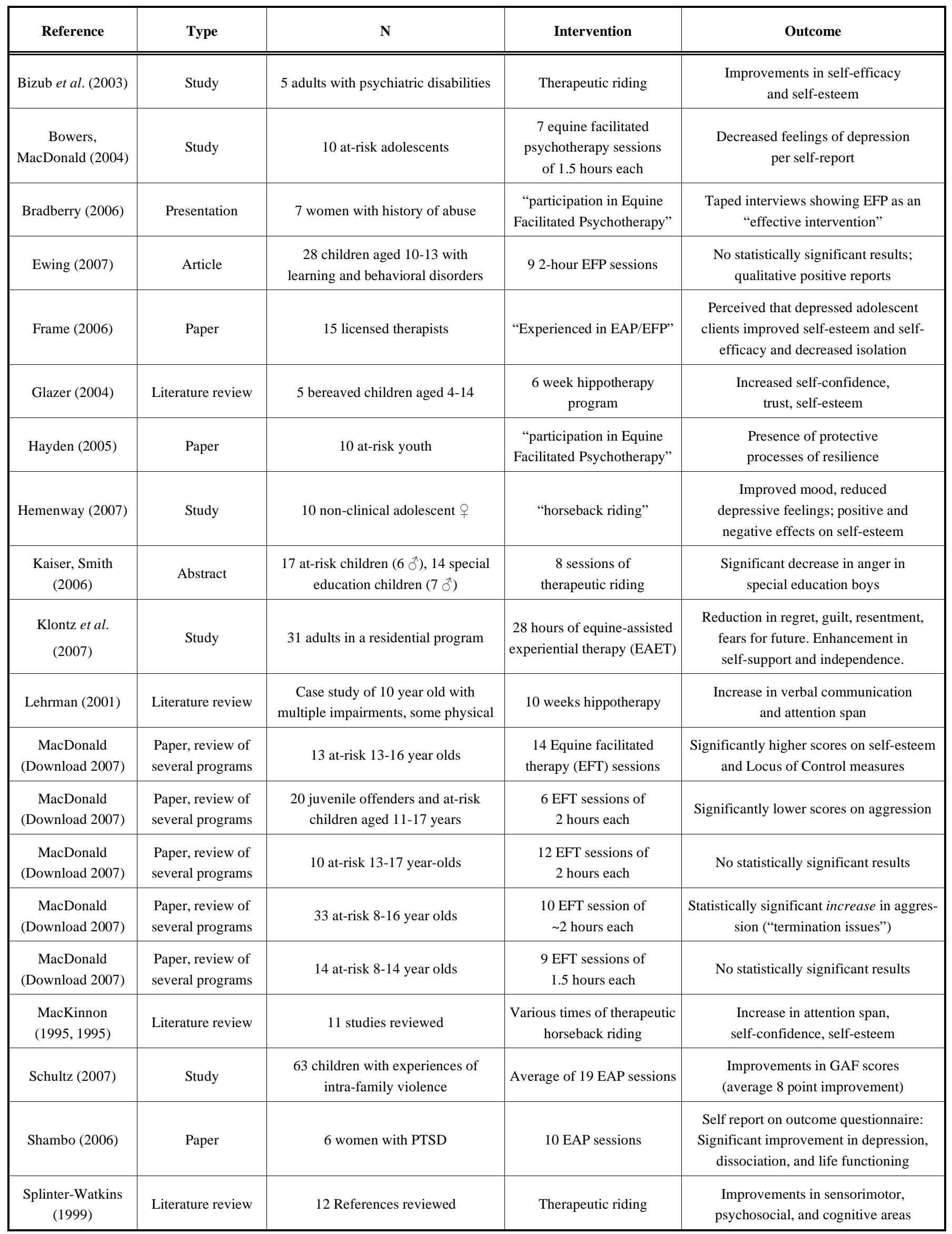


allowed to proceed at their own pace. They note the case of one gang boy who stated he initially did not like horses but eventually went through their program and left the gang to become a productive member of society, eventually joining Peace Corps. They recommend use of these methods when traditional psychotherapy fails.

\section{Quantitative Review}

Having described theory and practice, it is now time to turn to efficacy. The quantitative data (Table 1), presents findings from studies representing data from at least 300 participants. Their problems include abuse, behavioral disorders, being "at-risk" or juvenile offenders, "various mental health problems," post-traumatic stress disorder (PTSD), "in a residential facility," "psychiatric disability," and bereavement. Interventions varied from hippotherapy, to therapeutic riding, to EFP (equine facilitated psychotherapy), to EFT (equine-facilitated therapy), to EAET (equine-assisted experiential therapy). Outcomes measured also varied. They included "effective intervention"; qualitative positive results; decreased anger, aggression, depression, and dissociation; increased self-esteem, locus of control, global assessment of functioning, "life-functioning," self-confidence, self-esteem, attention-span, verbal communication, and "cognitive areas." One study mentioned some negative effects on the selfesteem of non-clinical adolescent girls. A particularly important noted negative outcome was increased aggression in another study. It was discussed whether attachment to and then loss of the animal could have been a factor leading to this negative finding. Positive outcomes in the above studies included decreases in anger, depression, dissociation, and aggression and increases in self-esteem, self-confidence, attention-span, and social interaction.

\section{DISCUSSION}

Considering all the varieties of method, style, technique and treatment groups described above, how is a therapist to make a choice about EFP in treatment with children and youths? Overall, the idea of this unconventional therapy is very appealing, especially for difficult to reach groups of patients. Mentioned several times were "therapy-wise" patients, hardened youths, and gangs. Furthermore, abused, eating-disordered, or neglected children who do not respond to the typical office therapy might also benefit. Also compelling was the theory of a holding environment and the related detail concerning similar ratios of horse/human versus mother/infant sizes.

While the described literature is quite fascinating, and possibly convincing on an individual basis, to get a conclusive evidence base on the efficacy of EFP for a particular population, a large multi-center study is needed. It should be standardized, controlled, and longitudinal. Additionally, the terminology, methods, and theories in this field are rather varied. Standardization of the language used to communicate between them would be recommended. The treatment population studied within a given study should be homogeneous and clearly described. Well-established, reliable and valid measures should be used to measure outcomes.

As Taylor [9] noted, like any developing field, EFP has at this time much more literature on practice than on research and theory and currently therapists fall into two groups: those who are willing to try out an "experimental" therapy and those who are waiting for more studies to come out. Longitudinal studies using biofeedback to measure physiologic heart rate variability, skin conductance level, and even beta vs. alpha brain wave activity, and blood samples measuring neurotransmitter uptake could significantly enhance research efforts.

Biofeedback was referred to in several articles. A noted point was how the natural gaits of a horse might promote relaxation and the alpha meditation state. It would be an especially remarkable study to pair already available software programs (Wild Divine) [25] that measure physiological biofeedback with equine facilitated psychotherapy. Physiological parameters tracked by these programs, such as previously mentioned skin conductance and heart rate variability, could be used as outcome variables in such research.

Cautionary tales warned that specific goals should be delineated when embarking on this atypical therapy and the patient should have a clear idea that despite the use of an animal, EFP is not a recreational activity. The therapist should also be unambiguous in establishing boundaries with the patient since the treatment is done in a non-conventional setting and therefore limits could possibly be confused or blurred.

Regarding obtaining sound and conclusive evidence for the quality and efficacy of EFP, the following design is recommended: 1) multi-center, 2) standardized types of EFP compared in different treatment arms, vaulting vs. animal care vs. riding vs. non-riding, 3) longitudinal (pre-treatment, and at least 2 years post-treatment), 4) controlled (using a treatment-as-usual control group), 5) outcomes of four types: cognitive, emotional, behavioral, and objective physiological variables.

\section{REFERENCES}

[1] Gamache J. Equine-assisted therapy's affect on social skills and attention among school age children. Paper for University of Puget Sound, Tacoma, WA 2004.

[2] Engel BT. The horse as a modality for occupational therapy. Occup Ther Health Care 1984; 1: 41-7.

[3] Brooks SM. Animal-Assisted Psychotherapy and Equine-Facilitated Psychotherapy. Working with Traumatized Youth in Child Welfare. Guilford Publications: New York 2006.

[4] Fine AH. Handbook on Animal Assisted Therapy: Theoretical Foundations and Guidelines for Practice. Academic Press Publications: London 2006.

[5] Lacoff SL, Boris M. Levinson: a historical perspective. A focus on his work involving animal-assisted psychotherapy. Dissertation Abstracts International: Section B. Sci Eng 2000; 61(5-B): 2767.

[6] Nilson R. Equine-facilitated psychotherapy. Perspect Psychiat Care 2004; 40(2): 42.

[7] Gasalberti D. Alternative therapies for children and youth with special health care needs. J Pediatr Health Care 2006; 20(2): 133-6.

[8] Esbjorn RJ. When Horses Heal: A Qualitative Inquiry into Equine Facilitated Psychotherapy. Dissertation for Institute of Transpersonal Psychology: Palo Alto, CA 2006.

[9] Taylor SM. Equine facilitated psychotherapy: an emerging field. Masters paper for Saint Michael's College, Colchester: Vermont 2001.

[10] Voelker R. Puppy love can be therapeutic, too. JAMA 1995; 274(24): 1897-9.

[11] Tyler JJ. Equine psychotherapy: worth more than just a horse laugh. Women Ther 1994; 15(3/4): 139-46.

[12] Roberts F, Bradberry J, Williams C. Equine-faciliataed psychotherapy benefits students and children. Holist Nurs Pract 2004; 18(1): 32-5. 
[13] Christian JE. All creatures great and small: utilizing equine-assisted therapy to treat eating disorders. J Psychol Christ 2005; 24(1): 657.

[14] Cumella EJ, Simpson S. Efficacy of equine therapy: mounting evidence. 2007; www.remudaranch.com

[15] Bates, A. Of patients \& horses: equine-facilitated psychotherapy. J Psychosoc Nurs Ment Health Serv 2002; 40(5): 16-9.

[16] Vidrine M, Owen-Smith P, Faulkner P. Equine-facilitated group psychotherapy: applications for therapeutic vaulting. Issues in Ment Health Nurs 2002; 23: 587-603.

[17] Colclasure D. To greener pastures. American Fitness Jul/Aug 2004.

[18] Scheidhacker M. The dynamic of a special three-way relationship: patient-horse-therapist in psychotherapeutic riding. Proceedings of the Ninth International Therapeutic Riding Congress: Riding the Winds of Change (28-36). Denver: North American Riding for the Handicapped Association 1997.
[19] McCormick AR, McCormick MD. Horse Sense and the Human Heart. Health Communications, Inc: Deerfield Beach, FL 1997.

[20] Karol J. Applying a traditional individual psychotherapy model to equine-facilitated psychotherapy (EFP): theory and method. Clin Child Psychol Psychiatry 2007; 12(1): 77-90.

[21] Kaiser L, Smith KA, Heleski CR, Spence LJ. Effects of a therapeutic riding program on at-risk and special education children. $\mathrm{J}$ Am Vet Med Assoc 2006; 228(1): 46-52.

[22] Moors D, Ed. Horse Hero: Biography of a Horse who Helps Children and Adults as a Therapy Horse. Horse and Rider: Golden, Co 2003.

[23] McCann J. Equine equilibrium. ASU Research, Spring: New York 2005.

[24] Marx RD, Cumella EJ. Is equine therapy useful in the treatment of eating disorders? Eat Disord 2003; 11: 143-7.

[25] Wild Divine (2008) www.wilddivine.com

(C) Lentini and Knox; Licensee Bentham Open.

This is an open access article licensed under the terms of the Creative Commons Attribution Non-Commercial License (http://creativecommons.org/licenses/ by-nc/3.0/) which permits unrestricted, non-commercial use, distribution and reproduction in any medium, provided the work is properly cited. 